\section{Scientific journal}

PHYSICAL AND MATHEMATICAL EDUCATION

Has been issued since 2013.

Науковий журнал

ФІЗИКО-МАТЕМАТИЧНА ОСВІТА

Видається з 2013.
ISSN 2413-158X (online)

ISSN 2413-1571 (print)

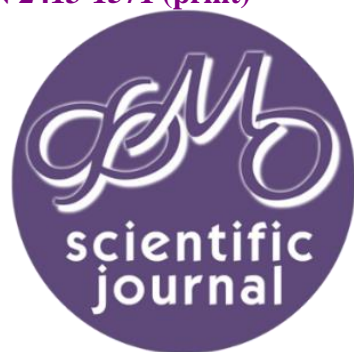

Друшляк М.Г., Шамоня В.Г. Системний підхід до формування візуально-інформаційної культури майбутніх учителів математики та інформатики. Фізико-математична освіта. 2021. Випуск 1(27). С. 45-49.

Drushlyak M., Shamonia V. A systematic approach to the formation of visual and information culture pre-service mathematics and computer science teachers. Physical and Mathematical Education. 2021. Issue 1(27). P. 45-49.

DOI 10.31110/2413-1571-2021-027-1-007

удк 378.14: 371.214.46

М.Г. Друшляк

Сумський державний педагогічний університет імені А.С. Макаренка, Україна marydru@fizmatsspu.sumy.ua ORCID: 0000-0002-9648-2248

В.Г. Шамоня

Сумський державний педагогічний університет імені А.С.Макаренка, Україна shamona@gmail.com

ORCID: 0000-0002-3201-4090

\title{
СИСТЕМНИЙ ПІДХІД ДО ФОРМУВАННЯ ВІЗУАЛЬНО-ІНФОРМАЦІЙНОЇ КУЛЬТУРИ МАЙБУТНІХ УЧИТЕЛІВ МАТЕМАТИКИ ТА ІНФОРМАТИКИ
}

\section{АНОТАЦІЯ}

Формулювання проблеми. На сьогодні спостерігається зміна способу сприйняття інформації молоддю, що призводить до затребуваності висококваліфікованих фахівців, зокрема вчителів, із високим рівнем сформованості візуальноінформаційної культури. Але формування візуально-інформаційної культури майбутніх учителів математики $i$ інформатики повинно відбуватися не фрагментарно, “від випадку до випадку», а у межах педагогічної системи, спираючись на системний підхід як на провідний методологічний підхід.

Матеріали і методи. Основою дослідження стали наукові розвідки вітчизняних і закордонних учених, які займаються вивченням питань підготовки майбутніх вчителів математики та інформатики, а також досліджують концептуальні основи і принципи системного підходу у підготовці фахівців. Для досягнення мети були використані методи теоретичного рівня наукового пізнання: аналіз наукової літератури, синтез, формалізація наукових джерел, опис, зіставлення.

Результати. 3 позицій системного підходу педагогічна система формування візуально-інформаційної культури майбутніх учителів математики та інформатики розглядалася як відкрита (взаємодіє з іншими системами), динамічна (ії змістове та організаційно-технологічне наповнення постійно удосконалюється) система, яка реалізується в єдності загального (формування візуально-інформаційної культури є частиною фахової підготовки майбутніх вчителів математики та інформатики), особливого (притаманні специфічні особливості математичної освіти, інформатичної освіти, наявність спеціалізованого програмного забезпечення), індивідуального (враховуються індивідуальні особливості студентів та особливості освітнього процесу конкретного закладу вищої освіти). У контексті дослідження системний підхід дозволяє розглядати процес формування візуально-інформаційної культури майбутніх учителів математики та інформатики як складний цілісний динамічний процес, який зорієнтований на досягнення певної мети і передбачає системний науковометодичний супровід окремих інформатико-математичних курсів і спецкурсів, чілеспрямоване удосконалення системи неперервної післядипломної освіти педагогічних працівників та тематики кваліфікаційних робіт.

Висновки. Ефективне формування візуально-інформаційної культури майбутніх учителів математики та інформатики забезпечується наступними положеннями: процес формування візуально-інформаційної культури майбутніх учителів математики та інформатики грунтується на системному підході та виваженому поєднанні інформатикоматематичної, педагогічної й інформаційної підготовки; оновлення змісту професійної підготовки майбутніх учителів математики та інформатики шляхом розробки науково-методичного супроводу окремих інформатикоматематичних курсів і спецкурсів; створення умов для реалізації індивідуальних освітніх траєкторії, раціонального та виваженого використання спеціалізованого програмного забезпечення, візуалізованих завдань, цілеспрямованого формування умінь критично оцінити та раціонально обрати комп'ютерний інструментарій; використання поширених та інноваційних форм, методів й засобів навчання для збалансованого співвідношення між теорією і практикою в освітній і професійній діяльності з метою формування умінь і навичок роботи з візуалізованим навчальним матеріалом.

ключовІ словА: система, педагогічна система, системний підхід, візуально-інформаційна культура, майбутні вчителі математики та інформатики. 


\section{ВСТУП}

Постановка проблеми. На сьогодні спостерігається зміна способу сприйняття інформації молоддю, що призводить до затребуваності висококваліфікованих фахівців, зокрема вчителів, із високим рівнем сформованості, так званої візуально-інформаційної культури, що проявляється у вмінні критично оцінювати інформаційний контент, якісно без втрати змісту стиснути його до наочного образу, бути спроможним знайти, інтерпретувати та узагальнити інформацію, за потреби представляти їі суб'єктивний і об'єктивний аналіз, візуально структурувати інформацію. Вчитель математики та інформатики має високий рівень сформованості візуально-інформаційна культури, якщо він здатний сприймати, інтерпретувати, продукувати інформацію подану візуально, уміє аналізувати, порівнювати, співставляти, інтегрувати, оцінювати, структурувати навчальну інформацію, уміє взаємодіяти з когнітивно-візуальними моделями, йому притаманна здатність до аналізу, прогнозування, рефлексії власної професійної діяльності, яка забезпечує професійний творчий саморозвиток, самовдосконалення й підвищення фахового рівня.

Але формування візуально-інформаційної культури майбутніх учителів математики і інформатики повинно відбуватися не фрагментарно, «від випадку до випадку», а у межах педагогічної системи, спираючись на системний підхід як на провідний методологічний підхід.

3 орієнтацією на системний підхід досліджувані об'єкти і явища сприймаються як педагогічна система з усіма притаманними їй властивостями, особливостями й закономірностями. Відповідно, самостійні компоненти педагогічного процесу (мета, завдання, зміст, форми і методи навчання) розглядаються не ізольовано, а у взаємодії, розвитку та русі, що дає змогу виявляти їх загальні системні властивості та якісні характеристики, які не зводяться до механічної суми їх складових. У результаті взаємодії компонентів і їх об'єднання в більші одиниці з'являються нові властивості, які не притаманні окремим частинам цілого і які не були виявлені на попередньому рівні організації.

Мета статті. Обґрунтувати доцільність формування візуально-інформаційної культури майбутніх учителів математики та інформатики у закладах вищої освіти на засадах системного підходу.

\section{МЕТОДИ ДОСЛІДЖЕННЯ}

Основою дослідження стали наукові розвідки вітчизняних і закордонних учених, які займаються вивченням питань підготовки майбутніх вчителів математики та інформатики, а також досліджують концептуальні основи і принципи системного підходу у підготовці фахівців. Для досягнення мети були використані методи теоретичного рівня наукового пізнання: аналіз наукової літератури, синтез, формалізація наукових джерел, опис, зіставлення.

\section{РЕЗУЛЬТАТИ}

3 позицій системного підходу педагогічна система формування візуально-інформаційної культури майбутніх учителів математики та інформатики розглядалася як відкрита (взаємодіє з іншими системами), динамічна (ії змістове та організаційно-технологічне наповнення постійно удосконалюється) система, яка реалізується в єдності загального (формування візуально-інформаційної культури $є$ частиною фахової підготовки майбутніх вчителів математики та інформатики), особливого (притаманні специфічні особливості математичної освіти, інформатичної освіти, наявність спеціалізованого програмного забезпечення), індивідуального (враховуються індивідуальні особливості студентів та особливості освітнього процесу конкретного закладу вищої освіти).

У контексті дослідження системний підхід дозволяє розглядати процес формування візуально-інформаційної культури майбутніх учителів математики та інформатики як складний цілісний динамічний процес, який зорієнтований на досягнення певної мети і передбачає системний науково-методичний супровід окремих інформатико-математичних курсів і спецкурсів, цілеспрямоване удосконалення системи неперервної післядипломної освіти педагогічних працівників та тематики кваліфікаційних робіт.

\section{ОБГОВОРЕННЯ}

Поняття система (від грецьк. бибтена - ціле, складене з частин; з'єднання) розуміється як "сукупність взаємопов' язаних елементів, які перебувають у відношенні і зв'язках один з одним, що утворює певну цілісність, єдність» (Блауберг \& Юдин, 1973).

Концептуальні основи і принципи системного підходу вперше були сформульовані російським ученим А. Богдановим, доповнені австрійцем Л. фон Берталанфі (L. Von Bertalanffy) та в подальшому наслідувалися В. Афанасьєвим (Афанасьев, 1980), Ю. Бабанським, В. Беспальком (Беспалько, 1977), М. Каганом, С. Харченко (Системний підхід у сучасних педагогічних дослідженнях в Україні, 2016) та ін.

3 позицій системного підходу основними ознаками системи $є$, по-перше, наявність системної якості, на що вказує В. Афанасьєв, визначаючи систему «як сукупність об'єктів, взаємодія яких обумовлює наявність нових інтегративних якостей, не властивих їі частинам, компонентам» (Афанасьев, 1980), по-друге, компоненти системи (структурні одиниці, частини системи, які взаємодіють з іншими структурними одиницями в рамках даної цілісної системи), по-третє, структура системи (упорядкованість внутрішніх і зовнішніх зв'язків об'єкту, що забезпечують його стійкість, стабільність, якісну визначеність) (Системний підхід у сучасних педагогічних дослідженнях в Україні, 2016).

На думку С. Харченка, методологічне значення мають наступні ознаки педагогічної системи: цілісність (частини педагогічної системи підпорядковуються спільній меті), взаємозв'язок (зміна одного параметра системи впливає на інші), зв'язок із зовнішнім середовищем (педагогічна система - це складова частина середовища, що включає елементи більш високого порядку) (Системний підхід у сучасних педагогічних дослідженнях в Україні, 2016).

3 метою реалізації авторського задуму формування візуально-інформаційної культури майбутніх учителів математики та інформатики відбувається у межах педагогічної системи, спираючись на системний підхід як на провідний методологічний підхід нашого дослідження. 
Ґрунтуючись на системному підході як на провідному, потрібно передбачити виконання наступних завдань: визначення мети системи, конструювання досліджуваного об'єкту як системи, побудова моделі системи, встановлення властивостей системи, дослідження функціонування системи.

В педагогіці системний підхід використовується з метою розробки методів дослідження й конструювання складних за організацією об'єктів як систем, розкриття їх цілісності, виявленні в них різноманітних типів зв'язків та зведення у єдину теоретичну картину (Гончаренко, 1997).

У психолого-педагогічній та методичній літературі описано ряд взаємопов'язаних систем: педагогічна, дидактична, методична тощо.

В. Беспалько стверджує, що введенням поняття «педагогічна система» "долається зовнішня безпредметність педагогічної науки: педагогічна система і $€$ ії предмет. Його повноцінному дослідженню й буде зобов'язана своїм майбутнім становленням і розвитком педагогіка як наука» (Беспалько, 1977). В. Беспалько педагогічною системою називає певну сукупність взаємопов'язаних засобів, методів і процесів, необхідних для створення організованого, цілеспрямованого та умисного педагогічного впливу на формування особистості із заданими якостями (Беспалько, 1977). С. Кушнірук, визначає поняття «педагогічна система» як полісистемне утворення (цілісність), що складається з багатьох взаємодіючих і взаємодоповнюючих частин, розглядає його у широкому і вузькому розумінні. У широкому розумінні це: 1) об'єднання учасників педагогічного процесу, в якому висувається мета і розв'язання педагогічних задач; 2) об'єднання учасників педагогічного процесу, де їх діяльність (пізнавальна, навчальна, трудова, моральна, художньо-естетична, ігрова та ін.) $€$ джерелом педагогічної мети і засобом ї̈ досягнення одночасно. У вузькому розумінні педагогічна система - це: 1) упорядкована кількість взаємопов'язаних компонентів, які утворюють єдине ціле і підпорядковані цілям виховання і навчання; 2) соціально обумовлена цілісність учасників педагогічного процесу з їх матеріальними і духовними цінностями, що взаємодіють на основі співробітництва між собою та з навколишнім середовищем, котра спрямована на формування і розвиток особистості (Кушнерук, 2008).

Н. Кузьміна розуміє «педагогічну систему» як «множину взаємопов'язаних структурних і функціональних компонентів, що підпорядковані цілям виховання, освіти і навчання молодого покоління та дорослих людей» (Методы системного педагогического исследования, 1980). За Н. Кузьміною структурні компоненти - це основні базові характеристики педагогічних систем, сукупність яких утворює факт їхньої наявності й відрізняє від усіх інших (непедагогічних) систем; це цілі навчання, зміст (навчальна інформація), засоби педагогічної комунікації (форми, методи, засоби навчання), суб'єкт (учитель), об'єкт (учень) [там само, с. 10-12]. Функціональні компоненти - це стійкі базові зв'язки основних структурних компонентів, що виникають у процесі діяльності керівництва, педагогів і учнів, і обумовлюють рух, розвиток, удосконалення педагогічних систем і внаслідок цього їхню стійкість і життєздатність; це гностичний, проєктувальний, конструктивний, комунікативний, організаторський функціональні компоненти (Методы системного педагогического исследования, 1980).

Л. Вікторова доповнює дане означення, додаючи до структурних компонентів педагогічної системи результат, аргументуючи це тим, що «критерієм ефективності діяльності системи може бути тільки рівень успішності тієі системи, для якої готується учень, будь то школа, ВН3 чи виробництво», а до функціональних - корективний (регулюючий) компонент для «корекцій проміжних відхилень попередніх результатів від часткових цілей та відхилень кінцевого результату від початкових цілей» (Викторова, 1989).

Щодо дидактичної системи, то її розглядають як складову педагогічної системи: як систему управління навчанням (Беспалько, 1977); як сукупність взаємозалежних між собою дидактичних компонентів (зміст, принципи, форми, методи, засоби навчання тощо) в основі дидактичних підсистем (теорій, концепцій тощо), функціональність яких залежить від загальних парадигмальних (визначених історичними обставинами та суспільними потребами) вимог (Осадченко, 2010). Як зазначає І. Сорокіна, найчастіше дидактичну систему розуміють як сформовану наукову теорію навчання, як тип організації навчання, який реалізується через певну сукупність ідей, що утворюють цілеспрямовану єдину і цілісну структуру. Наприклад, дидактична система навчання Л.Занкова, дидактична система розвиваючого навчання Д. Ельконіна-В. Давидова тощо (Сорокина, 2015).

Н. Грицай вважає, що проєктуючи дидактичну систему на навчання конкретного предмета, отримуємо методичну систему (Грицай, 2015). На думку І. Сорокіної методична система складається в педагогічній практиці викладача, визначається його професійно-особистісними якостями, рівнем розвитку його методичної компетентності (Сорокина, 2015).

3 ієрархії «педагогічна система - дидактична система - методична система» ми обираємо саме педагогічну систему як таку, що найбільш адекватно відповідає особливостям об'єкту дослідження, а саме процесу підготовки майбутніх учителів математики та інформатики у певному середовищі - закладі вищої освіти, і передбачає досягнення кінцевої мети - сформованості певної інтегративної якості особистості - візуально-інформаційної культури майбутніх учителів математики та інформатики.

Зауважимо, що педагогічні системи - це специфічні системи і тому потрібно враховувати їх особливості. На функціонуванні педагогічної системи позначається цілий ряд факторів, які не входять в систему як елементи, але значно відбиваються на їі стані і тенденціях розвитку. Серед таких факторів можна виділити соціальне замовлення суспільства; стан і тенденції розвитку педагогічної науки, що призводять до зміни педагогічних цілей і виникнення нових завдань, постійного оновлення навчальної інформації, яке відбивається на модернізації змісту навчання, постійного вдосконалення методів, засобів і форм навчання. 3 іншого боку впровадження педагогічної системи ініціює перетворення оточення відповідно до поставлених цілей. До того ж педагогічні системи знаходяться в неперервному процесі саморозвитку.

3 позицій системного підходу формування візуально-інформаційної культури майбутніх учителів математики та інформатики відбувається у межах відкритої (взаємодіє з іншими системами), динамічної (ії змістове та організаційнотехнологічне наповнення постійно удосконалюється) системи, яка реалізується в єдності загального (формування візуально-інформаційної культури є частиною фахової підготовки майбутніх вчителів математики та інформатики), 
особливого (притаманні специфічні особливості математичної освіти, інформатичної освіти, наявність спеціалізованого програмного забезпечення), індивідуального (враховуються індивідуальні особливості студентів та особливості освітнього процесу конкретного закладу вищої освіти).

У контексті дослідження системний підхід дозволяє розглядати педагогічну систему формування візуальноінформаційної культури майбутніх учителів математики та інформатики як складну цілісну динамічну систему, яка:

- зорієнтована на досягнення певної мети, що пов'язує у єдине ціле всі взаємодіючі компоненти системи;

- передбачає системний науково-методичний супровід окремих інформатико-математичних курсів і спецкурсів та удосконалення тематики кваліфікаційних (бакалаврських, магістерських) робіт;

- забезпечується поетапним впровадженням у освітній процес;

- спрямована на безперервний розвиток та професійне самовдосконалення учителів математики та інформатики у процесі неперервної післядипломної освіти педагогічних працівників.

Модель педагогічної системи формування візуально-інформаційної культури майбутніх учителів математики та інформатики у закладах вищої освіти ідеалізує внутрішню структурну організацію досліджуваного процесу, послідовно відтворює безперервність і поетапність формування такої культури, надає можливість досліджувати не увесь процес, а лише ті аспекти, які нас цікавлять, а також дозволяє раціонально спланувати експеримент.

Розроблено та теоретично обґрунтовано педагогічну систему формування візуально-інформаційної культури майбутніх учителів математики та інформатики у закладах вищої освіти, яка подано у єдності структурних компонентів: методологічно-цільова, змістово-процесуальна, діагностично-результативна підсистеми) і детально описано у (Друшляк, 2019).

\section{ВИСновкИ}

Системний підхід розглядає процес вивчення об'єктів і явищ як педагогічну систему з усіма притаманними їй властивостями, особливостями й закономірностями. Відповідно, самостійні компоненти педагогічного процесу (мета, завдання, зміст, форма і методи навчання) розглядаються не ізольовано, а у взаємодії, розвитку та русі, що дає змогу виявляти їх загальні системні властивості та якісні характеристики, які не зводяться до механічної суми їх складових. У результаті взаємодії компонентів і їх об'єднання в більші одиниці з'являються нові властивості, які не притаманні окремим частинам цілого і які не були виявлені на попередньому рівні організації.

Побудова педагогічної системи ґрунтується на припущенні, що ефективне формування візуально-інформаційної культури майбутніх учителів математики та інформатики забезпечується наступними положеннями:

- процес формування візуально-інформаційної культури майбутніх учителів математики та інформатики грунтується на діалектичному, системному, культурологічному, акмеологічному, синергетичному, особистісно орієнтованому, компетентнісному, когнітивно-візуальному, праксеологічному та BYOD підходах і визначається специфічними принципами технологічності, орієнтації на інформаційні технології, інтегрованості, студентоцентризма, використання доповненої реальності та виваженим поєднанням інформатико-математичної, педагогічної й інформаційної підготовки;

- оновлення змісту професійної підготовки майбутніх учителів математики та інформатики шляхом розробки науково-методичного супроводу окремих інформатико-математичних курсів і спецкурсів (навчальні програми, силабуси, короткі матеріали лекцій, лабораторних занять, матеріали для контролю знань, завдання для самостійної роботи та виконання індивідуально-дослідницьких завдань тощо) за результатами аналізу освітніх програм, навчальних планів та змісту освітніх компонентів;

- створення умов для реалізації індивідуальних освітніх траєкторії, раціонального та виваженого використання спеціалізованого програмного забезпечення, візуалізованих завдань, цілеспрямованого формування умінь критично оцінити та раціонально обрати комп'ютерний інструментарій;

- використання поширених та інноваційних форм, методів й засобів навчання для збалансованого співвідношення між теорією і практикою в освітній і професійній діяльності з метою формування умінь і навичок роботи з візуалізованим навчальним матеріалом (розробка, аналіз, використання у професійній діяльності тощо).

\section{Список використаних джерел}

1. Блауберг И. В, Юдин Є. Г. Становление и сущность системного похода. Москва: Наука, 1973. 271с.

2. Афанасьев В. Г. Системность и общество. Москва: Политиздат, 1980. 368 с.

3. Беспалько В. П. Основы теории педагогических систем. Воронеж: Изд-во Воронежского ун-та, 1977. 244 с.

4. Системний підхід у сучасних педагогічних дослідженнях в Україні: монографія / за ред. С. Я. Харченка. Старобільськ: Вид-во ДЗ «ЛНУ імені Тараса Шевченка», 2016. 488 с.

5. Гончаренко С.У. Український педагогічний словник. Київ: Либідь, 1997. 375 с.

6. Кушнерук С. А. Педагогічна система / Енциклопедія освіти / гол. ред. В. Г. Кремень. Київ: Юрінком Інтер, 2008. 1040 с.

7. Методы системного педагогического исследования / под ред. Н. В. Кузьминой. Ленинград: Изд-во Ленингр. ун-та, 1980. 172 c.

8. Осадченко І. Термінологічний аналіз дидактичних категорій: «система», «вид», «тип», «модель», «технологія». 3бірник наукових праць Уманського державного педагогічного університету ім. П. Тичини. 2010. Ч. 1. С. 217-226.

9. Сорокина И.В. Методическая система современного учителя как условие эффективности и результативности образовательного процесса. Поволжский педагогический вестник. 2015. №1 (6). С. 116-120

10. Грицай Н. Б. Структурні компоненти системи методичної підготовки майбутніх учителів біології. Science and Education a New Dimension. Pedagogy and Psychology. 2015. III(21), Is. 43. C. 21-24.

11. Друшляк М. Г. Система формування візуально-інформаційної культури майбутніх учителів математики та інформатики у закладах вищої освіти. Освіта. Інноватика. Практика. 2019. № 2(6). С. 10-17. 
References

1. Blauberg, I. V. \& Judin, Ye. G. (1973). Stanovlenie i sushhnost' sistemnogo pohoda [Formation of a systemic approach]. Moskva : Nauka. (in Russian)

2. Afanas'ev, V. G. (1980). Sistemnost' i obshhestvo [Systematicity and society]. Moskva: Politizdat. (in Russian)

3. Bespal'ko, V. P. (1977). Osnovy teorii pedagogicheskih sistem [Foundations of the theory of pedagogical systems]. Voronezh: Izd-vo Voronezhskogo un-ta. (in Russian)

4. Kharchenko, S. Ya. (Ed.). (2016). Systemnyi pidkhid u suchasnykh pedahohichnykh doslidzhenniakh v Ukraini : monohrafiia [System approach in modern pedagogical research in Ukraine: monograph]. Starobilsk: Vyd-vo DZ «LNU imeni Tarasa Shevchenka». (in Ukrainian)

5. Honcharenko, S.U. (1997). Ukrainskyi pedahohichnyi slovnyk [Ukrainian pedagogical dictionary]. Kyiv: Lybid. (in Ukrainian)

6. Kushneruk, S. A. (2008). Pedahohichna systema [Pedagogical system]. In V. H. Kremen (Ed.), Entsyklopediia osvity [Encyclopedia of Education]. Kyiv: Yurinkom Inter. (in Ukrainian)

7. Kuz'minoj, N. V. (Ed.). (1980). Metody sistemnogo pedagogicheskogo issledovanija [Methods of systemic pedagogical research]. Leningrad: Izd-vo Leningr. un-ta. (in Russian)

8. Osadchenko, I. (2010). Terminolohichnyi analiz dydaktychnykh katehorii: «systema», «vyd», «typ», «model», «tekhnolohiia» [Terminological analysis of didactic categories: "system", "type", "model", "technology"]. Zbirnyk naukovykh prats Umanskoho derzhavnoho pedahohichnoho universytetu im. P. Tychyny - Collection of scientific works of Uman State Pedagogical University named after $P$. Ticini, 1, 217-226. (in Ukrainian)

9. Sorokina, I. V. (2015). Metodicheskaja sistema sovremennogo uchitelja kak uslovie jeffektivnosti i rezul'tativnosti obrazovatel'nogo processa [Methodical system of a modern teacher as a condition of efficiency and effectiveness of the educational process]. Povolzhskij pedagogicheskij vestnik - Volga Pedagogical Bulletin, 1 (6), 116-120. (in Russian)

10. Hrytsai, N. B. (2015). Strukturni komponenty systemy metodychnoi pidhotovky maibutnikh uchyteliv biolohii [Structural components of the system of methodical training of future biology teachers]. Science and Education a New Dimension. Pedagogy and Psychology, III(21), 43, 21-24. (in Ukrainian)

11. Drushliak, M. H. (2019). Systema formuvannia vizualno-informatsiinoi kultury maibutnikh uchyteliv matematyky ta informatyky u zakladakh vyshchoi osvity [The system of formation of visual and information culture of pre-service mathematics and computer science teachers in higher education institutions]. Osvita. Innovatyka. Praktyka - Education. Innovation. Practice, 2(6), 10-17 (in Ukrainian)

\section{A SYSTEMATIC APPROACH TO THE FORMATION OF VISUAL AND INFORMATION CULTURE PRE-SERVICE MATHEMATICS AND COMPUTER SCIENCE TEACHERS \\ M.G. Drushlyak, V.G. Shamonia}

Abstract.

Makarenko Sumy State Pedagogical University, Ukraine

Formulation of the problem. Today there is a change in the way young people perceive information, which leads to the demand for highly qualified professionals, including teachers, with a high level of formation of visual and information culture. However, the formation of visual and information culture of pre-service mathematics and computer science teachers should not be fragmentary, "from case to case", but within the pedagogical system, based on a systematic approach as a leading methodological approach.

Materials and methods. The study was based on findings of national and foreign scientists who study the training of pre-service mathematics and computer science teachers, as well as explore the conceptual foundations and principles of a systematic approach to training. To achieve this goal, the methods of the theoretical level of scientific knowledge were used: analysis of scientific literature, synthesis, formalization of scientific sources, description, and comparison.

Results. From the standpoint of a systematic approach, the pedagogical system of formation of visual and information culture of pre-service mathematics and computer science teachers was considered as an open (interacts with other systems), dynamic (its content and organizational and technological content is constantly improving) system, which is implemented in the unity of general (formation of visual and information culture is part of the professional training of pre-service mathematics and computer science teachers), special (specific features of mathematical education, computer education, the availability of specialized software), individual (individual characteristics of students and educational features). process of a particular institution of higher education). In the context of the study, a systematic approach allows us to consider the process of formation of visual and information culture of pre-service mathematics and computer science teachers as a complex holistic dynamic process that focuses on achieving a specific goal and provides systematic scientific and methodological support of individual computer science and mathematics courses, purposeful improvement of the system of continuous postgraduate education of pedagogical workers and topics of qualification works.

Conclusions. The following provisions provide effective formation of visual and information culture of pre-service mathematics and computer science teachers. The first one: the process of formation of visual and information culture of pre-service mathematics and computer science teachers is based on a systematic approach and balanced combination of computer-mathematical, pedagogical and informational training. The second: updating the content of professional training of pre-service mathematics and computer science teachers is by developing scientific and methodological support for individual computer science and mathematics courses and special courses. The third: creating conditions for the implementation of individual educational trajectories, rational and balanced use of specialized software, visualized tasks, and purposeful formation of skills to critically evaluate and rationally choose computer tools. The forth: the use of common and innovative forms, methods and teaching aids for a balanced relationship between theory and practice in educational and professional activities in order to develop skills and abilities to work with visualized educational material.

Keywords: system, pedagogical system, system approach, visual and information culture, pre-service mathematics and computer science teachers.

\section{$(\mathrm{cc}) \mathrm{BY}-\mathrm{NC}-\mathrm{SA}$}

This work is licensed under Creative Commons Attribution-NonCommercial-ShareAlike 4.0 International License. 